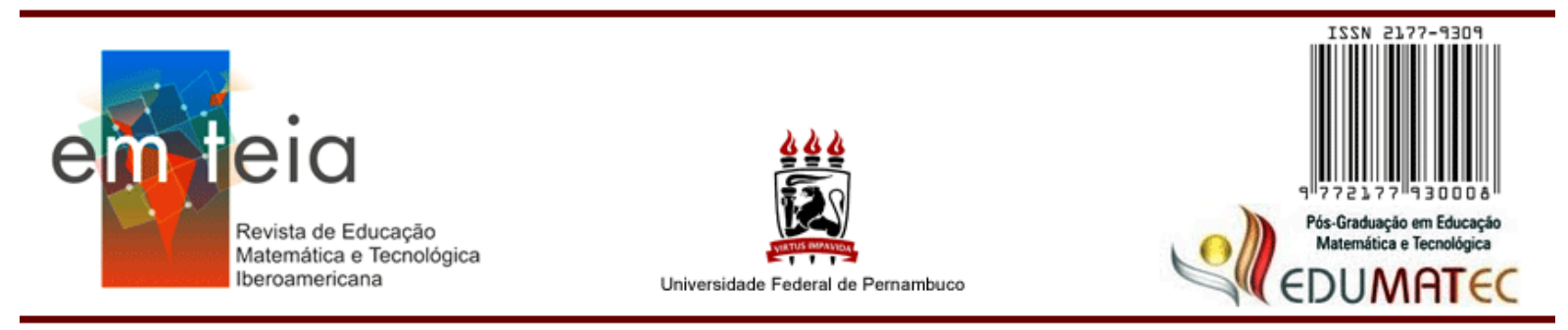

\title{
KHAN ACADEMY E O ENSINO/APRENDIZAGEM DE MATEMÁTICA PARA ALÉM DA SALA DE AULA
}

\author{
Khan Academy y la Enseñanza/Aprendizaje de las Matemáticas más allá del Aula
}

\author{
Renan Pereira Santos \\ Especialização em Metodologia do Ensino de Matemática \\ Secretaria da Educação do Estado da Bahia - Brasil \\ renan.psantos96@gmail.com \\ https://orcid.org/0000-0002-8331-4122
}

Antônio Carlos Bastos Sousa

Mestrado Profissional em Matemática Secretaria da Educação do Estado da Bahia - Brasil antoniocte@gmail.com https://orcid.org/0000-0002-5008-9133

\section{Resumo}

As Tecnologias Digitais de Informação e Comunicação (TDICs) estão cada vez mais presentes no cotidiano das crianças, adolescentes e jovens. Nesse contexto, a usabilidade das TDICs também tem encontrado espaço na Educação, num processo em que a utilização de recursos e ferramentas digitais tem promovido práticas educativas mais próximas desse cenário no qual os alunos da atualidade estão inseridos. A partir disso, este artigo discute a possibilidade de uso da plataforma Khan Academy como ferramenta de auxílio no ensino/aprendizagem de Matemática, apoiado na perspectiva do Ensino Híbrido e do conceito de Sala de Aula Ampliada. Para tal, este traz reflexões sobre o uso da TDICs na Educação e apresenta/discute a interface de funcionamento da plataforma em questão, acessibilidade e gamificação de conteúdos/atividades, a partir da literatura disponível sobre a temática. Apresenta também, os resultados de uma pesquisa de campo realizada com alunos de nível médio que, ainda que possam ser estendidos, considera a plataforma Khan Academy como ferramenta capaz de auxiliar no ensino/aprendizagem de Matemática, uma vez que pode atuar como ambiente para o complemento do estudo dos alunos, possibilitando estudar em casa, no horário que convém, com acesso a amplos conteúdos disponibilizados em vídeos, textos e exercícios que podem expandir o aprendizado tido em sala de aula.

Palavras-Chave: Khan Academy, Ensino/aprendizagem, Tecnologias Digitais de Informação e Comunicação, Sala de Aula Ampliada.

\section{Resumen}

Las Tecnologías de la Información y las Comunicaciones Digitales (TDIC's) están cada vez más presentes en la vida cotidiana de los niños, adolescentes y jóvenes. En este contexto, la usabilidad de los TDIC también ha encontrado espacio en la educación, en un proceso que el uso de recursos y herramientas digitales ha promovido prácticas educativas más cercanas a este escenario que se insertan los estudiantes de hoy. Con base en esto, este artículo discute la posibilidad de utilizar la plataforma Khan Academy como una herramienta para ayudar en la enseñanza/aprendizaje de las Matemáticas, apoyado por la perspectiva de la Enseñanza Híbrida y el concepto de Aula Extendida. Para ello, trae 
reflexiones sobre el uso de TDIC's en educación y presenta/discute la interfaz operativa de la plataforma en cuestión, accesibilidad y gamificación de contenidos/actividades, en base a la literatura disponible sobre el tema. También presenta los resultados de una investigación de campo realizada con estudiantes de secundaria que, si bien pueden ampliarse, consideran la plataforma Khan Academy como una herramienta capaz de ayudar en la enseñanza/aprendizaje de las Matemáticas, ya que puede actuar como un entorno para complementar el estudio de los alumnos, permitiéndoles estudiar en casa, en el momento que más les convenga, con acceso a un amplio contenido disponible en videos, textos y ejercicios que pueden ampliar los aprendizajes realizados en el aula.

Palabras clave: Khan Academy, Enseñanza/Aprendizaje, Tecnologías de la Información y la Comunicación Digitales, Aula Extendida.

\section{Introdução}

As Tecnologias Digitais de Informação e Comunicação (TDICs) estão presentes no dia a dia de todas as gerações: crianças, jovens, adultos e idosos. Todos estão cada vez mais inseridos nesse contexto no qual as tecnologias têm conquistado espaço. Não sendo ela a protagonista, mas o meio facilitador na resolução de necessidades atuais, sendo até mesmo ferramenta essencial em determinadas situações. A inovação tecnológica não é o vilão da humanidade e de seu desenvolvimento, podendo ser uma ferramenta importante para o desenvolvimento sustentável e a inclusão de povos e parcelas populacionais antes excluídas devido aos limites físicos e geográficos.

Quando se fala em geração e inovação, ouvimos falar naqueles que são chamados de "nativos digitais" - pessoas jovens que cresceram em ambientes ricos em tecnologias. Estes utilizam as tecnologias digitais cotidianamente para relacionar-se, divertir, compartilhar, comprar, informar-se e até mesmo estudar. A praticidade das TDICs abre possibilidades inesgotáveis de utilização.

Num processo que mantém suas bases pedagógicas e metodológicas, os professores podem encontrar, nesse contexto, recursos e ferramentas didáticas que promovam práticas educativas, mais próximas do cenário no qual os alunos da atualidade estão inseridos, promovendo, assim, maneiras mais interativas e inovadoras para o ensino/aprendizagem. Porém, não basta ceder ao fascínio das TDICs e não se trata apenas de ter acesso às informações, mas que elas possam auxiliar no processo de construção do saber.

No recorte do ensino/aprendizagem de Matemática, nas escolas brasileiras, são evidentes as diversas lacunas existentes que limitam o aprendizado. Para virar esse jogo seria necessária uma "mudança na postura e proposta pedagógica, adotando práticas educativas e metodologia conveniente para o ensino/aprendizagem da Matemática", como afirma Henriques (2002, p. 39). De acordo com o autor, as novas tecnologias são uma alternativa. 
A partir desse contexto, esse artigo busca discutir e analisar as possibilidades de uso como ferramenta de auxílio no ensino/aprendizagem de Matemática e as potencialidades, praticidade, usabilidade e funcionalidade da plataforma Khan Academy ${ }^{1}$, na perspectiva do Ensino Híbrido e do conceito de Sala de Aula Ampliada. Este traz ainda o resultado de uma investigação realizada com estudantes de duas escolas e suas opiniões em relação a plataforma mencionada a partir de vivências no ambiente.

\section{Recorte Teórico}

De acordo com Borba e Penteado (2007), hoje em dia, uma criança já nasce em contato com o celular e o computador. Logo, a escola e o professor não têm mais como ignorar a relação entre as TDICs e a Educação, pois esses podem atuar e colaborar mutuamente para a construção de conhecimento do estudante.

Logo, uma estratégia que lançam mão para o ensino e aprendizagem de Matemática é utilizar essas ferramentas digitais para ajudar na aprendizagem do educando. Segundo Libâneo (1996), essas ferramentas podem transmitir e difundir informações e/ou conhecimento tanto quanto o professor, porém, cabe ao professor ter papel mediador na interação aluno-tecnologia.

Diante dessa nova interação do aluno-professor-tecnologia no processo de ensino e aprendizagem, é necessário que isso faça sentido para o aluno. Isto é, para que seja possível alcançar resultados satisfatórios, não se deve utilizar aleatoriamente as TDICs. Devem-se escolher caminhos que possam proporcionar uma aprendizagem significativa - conceito desenvolvido por David Ausubel (1963) - para que faça sentido ao aluno e que seja absolvida e interiorizada por ele. Como aprendizagem significativa, Moreira (2005, p. 4-5) aponta que:

Sabemos que a aprendizagem significativa caracteriza-se pela interação cognitiva entre o novo conhecimento e o conhecimento prévio. Nesse processo, que é não literal e não arbitrário, o novo conhecimento adquire significados para o aprendiz e o conhecimento prévio fica mais rico, mais diferenciado, mais elaborado em termos de significados, e adquire mais estabilidade.

Ou seja, a aprendizagem é significativa para o estudante quando o que se aprende está relacionado com seu conhecimento prévio e faça sentido no contexto que está inserido. Dessa forma, o que se aprendeu ganha estabilidade e torna-se mais difícil de esquecer. Logo, a metodologia de ensino e os recursos didáticos utilizados pelo professor devem favorecer uma aprendizagem significativa e que o aluno realmente aprenda.

\footnotetext{
${ }^{1}$ Disponível em: < http://www.pt.khanacademy.org/>.
} 
E, sendo assim, a aprendizagem consolidada em saber perpassa por processos cognitivos-afetivos, tais como memorização, conhecimentos prévios, assimilação, ludicidade e satisfação, que, quando mediada por recursos tecnológicos digitais como as TDICs, pode ocorrer a partir da abordagem construcionista proposta por Papert (1994 e 1986), que diz respeito à construção do conhecimento baseada na realização de uma ação concreta que resulta em um produto palpável, desenvolvido com o concurso do computador, que seja de interesse de quem o produz. O construcionismo implica numa interação aluno-objeto, mediada por uma linguagem de programação.

O uso de tecnologia para o ensino e aprendizagem de Matemática também é o que preconiza a nova Base Nacional Comum Curricular (BNCC) para o Ensino Fundamental e Médio. Nas competências específicas de Matemática para o Ensino Fundamental, por exemplo, recomenda-se "utilizar processos e ferramentas matemáticas, inclusive tecnologias digitais disponíveis, para modelar e resolver problemas". Tal recomendação também está expressa na base para a etapa do ensino médio, bem como, acrescenta o objetivo de que o aluno seja estimulado a desenvolver o pensamento computacional, por meio da interpretação e da elaboração de algoritmos.

Diante disso, a utilização das tecnologias nas ações de ensino e aprendizagem, relacionando-as ao currículo escolar e integrando espaço presencial e online, é o que busca o Ensino Híbrido, que surge numa perspectiva de maior engajamento dos alunos no aprendizado, melhor aproveitamento do tempo do professor, ampliação do potencial da ação educativa, visando intervenções efetivas, planejamento personalizado, com acompanhamento de cada aluno (BACICH; NETO; TREVISANI, 2015). Ou seja, o Ensino Híbrido reconhece que as tecnologias e a Educação podem caminhar juntas e levar os alunos ao objetivo principal que é aprender e se preparar para a vida.

Para entender melhor, a palavra híbrido vem de misturado, mesclado, e essa ideia tem ligação direta com a finalidade do Ensino Híbrido, que é de combinar as vantagens da informática, da Educação online com todos os benefícios da sala de aula tradicional (CHRISTENSEN; HORN; STAKER, 2013). Vejamos que nenhuma sobrepõe a outra ou é considerada melhor ou mais eficiente, isso evidencia que o ensino híbrido vem para acrescentar ao processo de ensino e aprendizagem, ajudando o professor e o aluno.

O uso das TDICs como auxílio no processo ensino e aprendizagem de Matemática se apoia também na perspectiva da "sala de aula ampliada". Segundo Azevedo e Moraes (2017), essa perspectiva concede às ferramentas digitais a possibilidade de auxiliar na construção do 
conhecimento matemático, onde o professor exerce a função de mediador e tutor dos conteúdos ensinados, a partir das habilidades que os alunos do século XXI dominam e se interessam [tecnologias digitais de informação e comunicação], conduzindo a uma aprendizagem mais significativa e contextualizada.

Nessa categoria de sala de aula ampliada entende-se que as possibilidades de aprender rompem os limites da escola, como afirma Perico (2015, p. 101) que a ideia de sala de aula ampliada é "focar a continuidade dos estudos além do horário da aula e dos limites da escola. Trata-se do ensino e aprendizado em período integral, não condicionados ao horário de permanência na escola, mas relacionados ao aprendizado contínuo mediado pela tecnologia". Assim, os alunos utilizam as TDICs como uma boa oportunidade de ampliar seus estudos além do espaço e do horário escolar.

\section{A Plataforma Khan Academy}

A plataforma Khan Academy² é um ambiente virtual de aprendizagem original dos EUA e traduzido para o português, por meio da Fundação Lemann e disponibiliza vídeo aulas, artigos e exercícios que propiciam o aprendizado da Matemática e outras ciências, para qualquer pessoa de maneira personalizada, demonstrando habilidades dominadas e as quais precisam ser praticadas.

A forma que a Khan Academy disponibiliza o conhecimento para seus usuários baseado em exercícios (variando de acordo com a matéria selecionada) práticos e vídeo-aulas, envolve o usuário e torna prático e fácil de utilizar a plataforma, bem como facilita para o professor que, sendo o tutor, pode criar turmas e acompanhar o desempenho de seus alunos, de maneira coletiva e individual. Na Khan Academy é possível também que os próprios pais dos alunos sejam o tutor de seus filhos, podendo acompanhar e verificar o progresso do aprendizado através da internet.

Mas, afinal, o que tem de diferente a plataforma Khan Academy? De acordo com Menegais (2015), a Khan Academy apresenta uma metodologia que promove no aluno a curiosidade, possibilitando que este aprenda os conteúdos matemáticos de acordo com o seu próprio ritmo, aproveitando melhor o tempo de estudo em casa e permitindo que em sala de aula tenha mais tempo para tirar dúvidas do assunto estudado com o professor. Percebe-se que

\footnotetext{
${ }^{2}$ Para usar a plataforma, é preciso acessar o site da Khan Academy na internet ou baixar a ferramenta na loja de aplicativos do seu aparelho celular, e que o professor ou aluno tenha uma conta usuário para ter acesso ao conteúdo do site. Para criar a conta e fazer login na plataforma, o usuário pode se cadastrar com uma conta de email ou usando o login da conta do Facebook. Na página de cadastro tem a opção de escolha de perfis para alunos, pais e professores.
} 
essa é uma proposta interessante para aplicação no ensino de Matemática de acordo com a autora, que ainda destaca mais um diferencial da plataforma.

A sala de aula, então, passa a ser um lugar para discutir o assunto e tirar dúvidas, e não somente para aulas expositivas que, por vezes, não geram um diálogo construtivo. O diferencial da plataforma é a sua propriedade de adaptar-se aos conhecimentos prévios dos estudantes, indicando possibilidades de avanços a partir deles. (MENEGAIS, 2015, p. 12).

Ou seja, com a utilização dessa plataforma, é possível o aluno estudar, treinar e exercitar o conteúdo em casa ou outro ambiente fora da sala de aula e, na sala de aula, o professor de Matemática terá mais tempo para interagir e explorar as dificuldades gerais dos alunos e até mesmo de acompanhar, na medida do possível, as dificuldades individuais.

Sobre o mecanismo de funcionamento dessa ferramenta existem pontos e inovações importantes a se destacarem. Um primeiro aspecto interessante usado como pano de fundo pela Khan Academy é a estrutura gamificada. Gamificação do sistema de aprendizagem, como é conhecido pela literatura atual, refere-se à aplicação de elementos dos games fora do contexto dos games (FARDO, 2013), nesse caso aplicado às ferramentas educacionais. $\mathrm{Na}$ figura 1, temos o perfil de um aluno no qual vemos a quantidade de pontos de energia acumulados, níveis de habilidades conquistados e as medalhas adquiridas. Esses são exemplos de elementos utilizados em game, que aqui são utilizados no contexto educacional.

Figura 1: Tela do perfil de Aluno com o status de atividade, pontos de energia e medalhas, na plataforma Khan Academy.

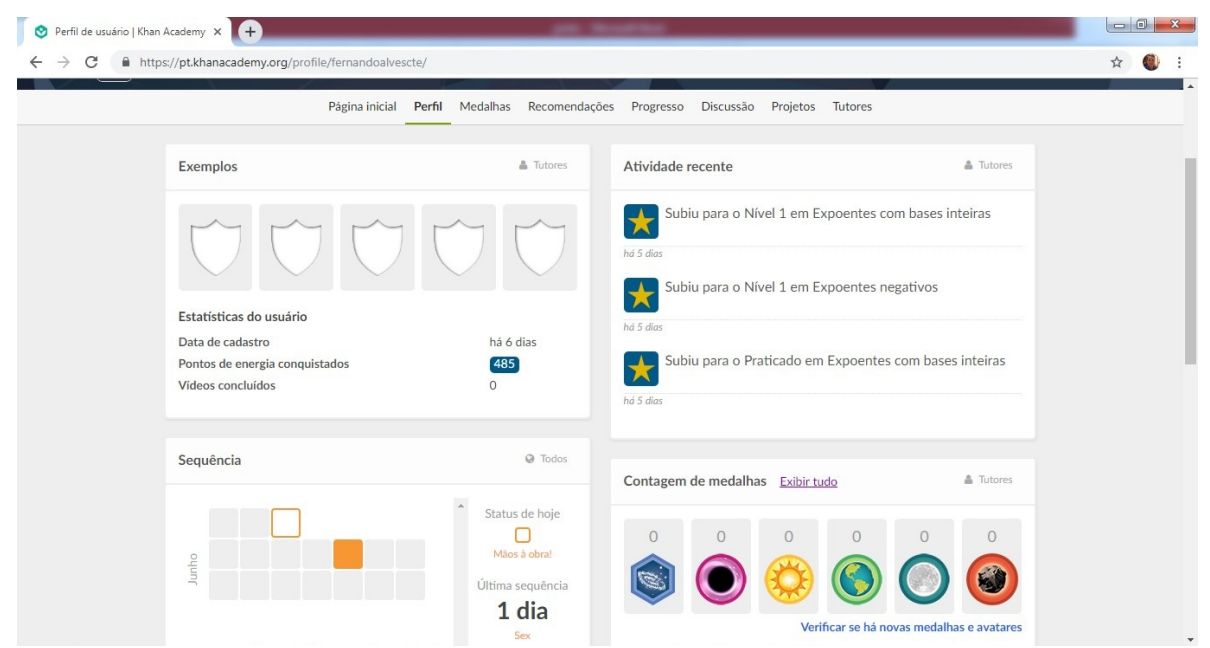

Fonte: Captura de tela na plataforma Khan Academy, 2019.

Diante disso, à medida que o aluno interage com a plataforma, seja através da audiência nas vídeo-aulas, leitura de artigos e resolução de exercícios, ele recebe recompensas por meio de energias e medalhas. "A plataforma Khan Academy oferece ao aluno ganho de 
pontos de energia quando o mesmo realiza uma atividade, concluindo-a ou não" e "as medalhas são outra forma de recompensa que o aluno recebe quando cumpre determinados requisitos, que a própria plataforma determina" (CORRÊA, 2016). Dessa forma, configura-se um incentivo a mais ao engajamento do aluno nas atividades e tarefas propostas pelo professor, pois ele é desafiado também a conquistar recompensas, acumular pontos de energia e medalhas, bem como a avançar de nível. É essa a ideia de games que está inserida na ferramenta e que é positivo para a aprendizagem.

Outra vantagem levantada por Menegais (2015) é que a plataforma começa a desenvolver a aprendizagem a partir do conhecimento prévio e das necessidades do aluno, ou seja, ele só avança quando dominar o pré-requisito do conteúdo. Isso facilita, por exemplo, a identificar qual a dificuldade que o aluno tem para aprender determinado conteúdo.

Essa metodologia do conteúdo dominado adotada pela Khan preconiza que a princípio é importante que o aluno estude um conteúdo até que ele possa dominar o que aprendeu, isto é, ele só poderá avançar de conteúdo quando atingir um aprendizado adequado do conceito do assunto estudado. De acordo com Duarte (2018), esse tipo de aprendizagem está alicerçado em metas de compreensão e realização do conhecimento, fugindo da estrutura engessada do currículo. Segundo ele, essa perspectiva altera o papel do professor que passa agir como um facilitador e não um mero expositor de conteúdos.

Sob a perspectiva pedagógica, a Khan Academy é uma ferramenta que personaliza a aprendizagem dos estudantes conforme suas necessidades e desempenho, ou seja, atende às dificuldades dos que precisam retornar aquilo que não aprendeu, bem como acompanha o progresso dos alunos com atividades mais avançados (DUARTE, 2018).

Quanto aos conteúdos do currículo de Matemática, a plataforma oferece um grande número, desde o Ensino Fundamental ao Ensino Superior, disponibilizando-os por assunto ou série. Os conteúdos já estão adaptados às exigências da nova $\mathrm{BNCC}$, relacionando os conteúdos com as habilidades e competências. A abordagem desses conteúdos também se apresenta de forma clara e objetiva na linguagem utilizada e de forma didática e dinâmica nos exercícios e tarefas propostos, utilizando inclusive recursos de geometria dinâmica ${ }^{3}$. Tal disposição dos conteúdos também facilita a navegação do aluno como se estivesse em uma trilha com informações, exercícios, tarefas e novidades, sendo assim, atraente e prazerosa.

\footnotetext{
${ }^{3}$ Geometria Dinâmica é a geometria proporcionada por programas gráficos que, numa área de desenho, permitem construções geométricas a partir de objetos-base, que atualizam automaticamente as construções sempre que o usuário alterar um dos objetos-base.
} 
De acordo com Duarte (2018), é importante destacar que na plataforma o erro é construtivo, diante da possibilidade de retornar e praticar mais no que se tem dificuldade. Segundo ele, todos esses pontos elencados "tornam o trabalho com a plataforma uma hipótese de melhoria na qualidade do aprendizado para os nativos digitais" (DUARTE, 2018, p. 30). Por isso, o uso da ferramenta torna familiar a aprendizagem daqueles que nasceram diante e arrodeados dos recursos digitais.

No entanto, vale ressaltar que o sucesso da utilização de um recurso pedagógico ou de uma ferramenta digital na Educação necessita da mediação adequada e bem orientada do professor. O papel docente é insubstituível e indispensável. Este, deve, inicialmente, conhecer bem o recurso e não se furtar da responsabilidade na relação aluno, tecnologia e conteúdo.

Desta forma, o simples uso de uma plataforma educativa, como a plataforma Khan Academy sem intervenção de um professor, sem atividades mediadas por professores podem não garantir um processo de aprendizagem e literacidade crítica de mídia e informação. O professor também necessita estar amparado por uma estrutura física, político, ideológica, filosófica e pedagógica dentro da escola que o auxiliem neste processo. (BIERWAGEN, 2018, p. 8)

Essa é uma observação importante a considerar, pois quando falamos do uso de ferramentas digitais não significa a substituição do professor e da aula presencial, e sim falamos de um recurso que venha acrescentar e/ou auxiliar o profissional docente e o trabalho em sala de aula. E, como um suporte ao trabalho docente e a sala de aula, essas ferramentas devem ser bem direcionadas para que seja alçado o êxito pela qual justifica sua utilização. Assim, com o devido conhecimento e acompanhamento da plataforma referida, essa poderá contribuir com a melhoria do ensino e aprendizagem.

\section{Caminhos da Pesquisa}

Numa pesquisa científica, de acordo com Bicudo (1993), "pesquisar configura-se como buscar compreensões e interpretações significativas do ponto de vista da interrogação formulada" (BICUDO, 1993, p. 18). Baseado nisso, realizamos pesquisa de campo em duas turmas: uma, do terceiro ano do Ensino Médio; e outra, do segundo ano do Ensino Médio Técnico em Administração, em instituições públicas. As atividades realizadas durante a investigação científica estão descritas no tópico a seguir.

Os estudantes que concordaram em participar da pesquisa, preencheram o formulário de inscrição e o termo de livre consentimento, sendo informados que iriam realizar novas experiências sobre o mesmo conteúdo estudado na sala de aula em um ambiente virtual de 
ensino e aprendizagem, tendo suas identificações pessoais preservadas. Coube também, aos autores deste artigo, a função de tutores nas turmas criadas na plataforma Khan Academy e o acompanhamento do progresso dos estudantes.

A coleta de dados foi realizada através de notas de campo por meio das ferramentas de tutoria da Khan Academy e de um questionário ${ }^{4}$ semiestruturado aplicado aos alunos. Para a análise dos dados, utilizamos a abordagem qualitativa que se fundamenta pelas suas características que evidenciam a natureza do comportamento empírico do fenômeno investigado. Para tal, assumimos as características de uma pesquisa de natureza qualitativa conceituadas por Bogdan e Biklen (1994).

E, para a análise das interfaces de funcionamento e usabilidade do ambiente da plataforma em questão, utilizamos a avaliação heurística. O Método de Avaliação Heurística, segundo RAPOSO (2012), foi proposto por Jakob Nielsen, em 1994, e trata-se de uma inspeção baseada em um conhecimento prático, fruto de uma experiência mediada por recursos digitais.

\section{Atividades Realizadas na Pesquisa}

A pesquisa desenvolveu-se em duas turmas e a proposta de trabalho das atividades serviriam de reforço aos estudantes para suprir suas dificuldades, complementar seus estudos e desenvolver as habilidades acerca do conteúdo estudado em sala de aula. Então, os conteúdos abordados nesse trabalho foram os mesmos que os alunos estavam estudando em suas respectivas salas de aula, a saber: Primas e Pirâmides, para um grupo de alunos do $3^{\circ}$ ano do Ensino Médio; e Função Exponencial, para um grupo de alunos do $2^{\circ}$ ano do Ensino Médio Técnico em Administração.

Diante disso, foi definida uma quantidade de tarefas entre vídeos e exercícios disponíveis na Khan Academy que eram relacionados com os conteúdos citados acima e recomendados a eles pelo ambiente. As tarefas foram recomendadas obedecendo uma ordem lógica dos assuntos e liberadas gradativamente para as respectivas turmas. Lembramos que quando um aluno faz o cadastro na Khan Academy ele tem a liberdade de escolher quaisquer conteúdos para estudar, porém, neste trabalho, buscamos analisar o comportamento de alunos, em turmas que estes realizassem atividades relacionadas com os assuntos da sala de aula e que fossem acompanhados por um professor-tutor.

\footnotetext{
${ }^{4}$ Questionário aplicado aos participantes da pesquisa: $<$ https://bityli.com/zS1bLH>.
} 
Para as atividades recomendas em cada turma, os alunos teriam que responder uma quantidade $x$ de questões escolhidas pela plataforma, dentre um conjunto de questões disponíveis sobre o assunto, as quais apenas o professor-tutor tem acesso às perguntas e respostas comentadas. Ao fazer uma recomendação de tarefa é possível ao professor escolher entre um conjunto de questões diferentes para cada aluno ou um mesmo conjunto de questões para todos os alunos, além do tempo de duração da atividade.

Figura 2: Primeira recomendação feita para a turma do $3^{\circ}$ ano EM.

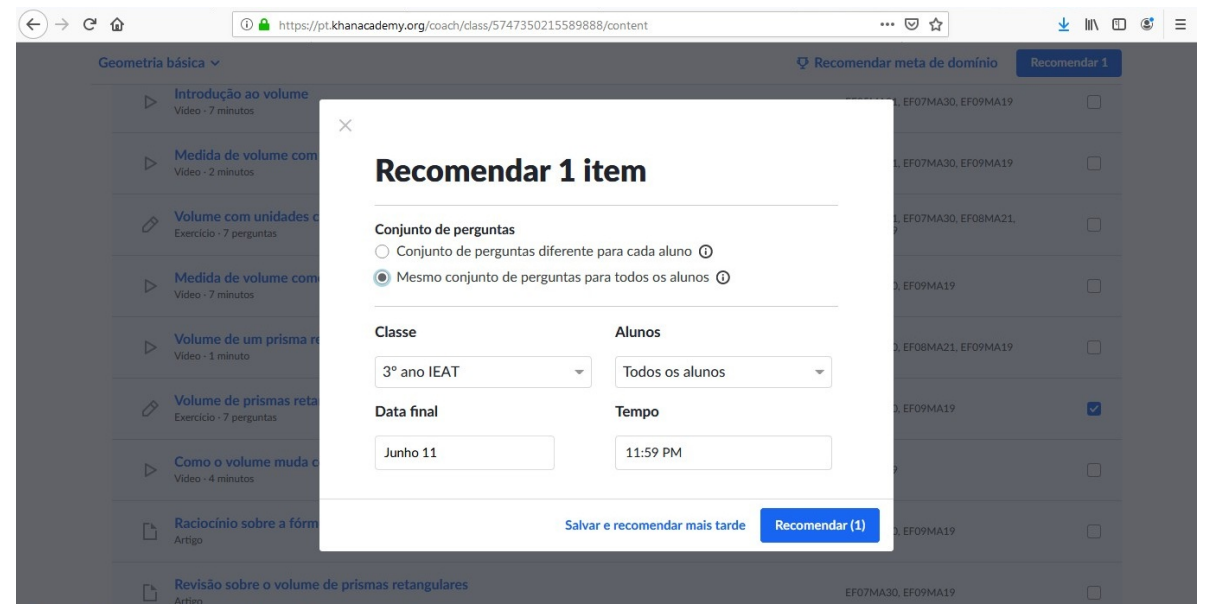

Fonte: Captura de tela na plataforma Khan Academy, 2019.

$\mathrm{Na}$ figura 3, temos a visualização do conjunto maior de questões do qual sairá as perguntas propostas aos alunos do conteúdo de volume de prismas regulares.

Figura 3: Questões da primeira recomendação feita para a turma do $3^{\circ}$ ano EM.

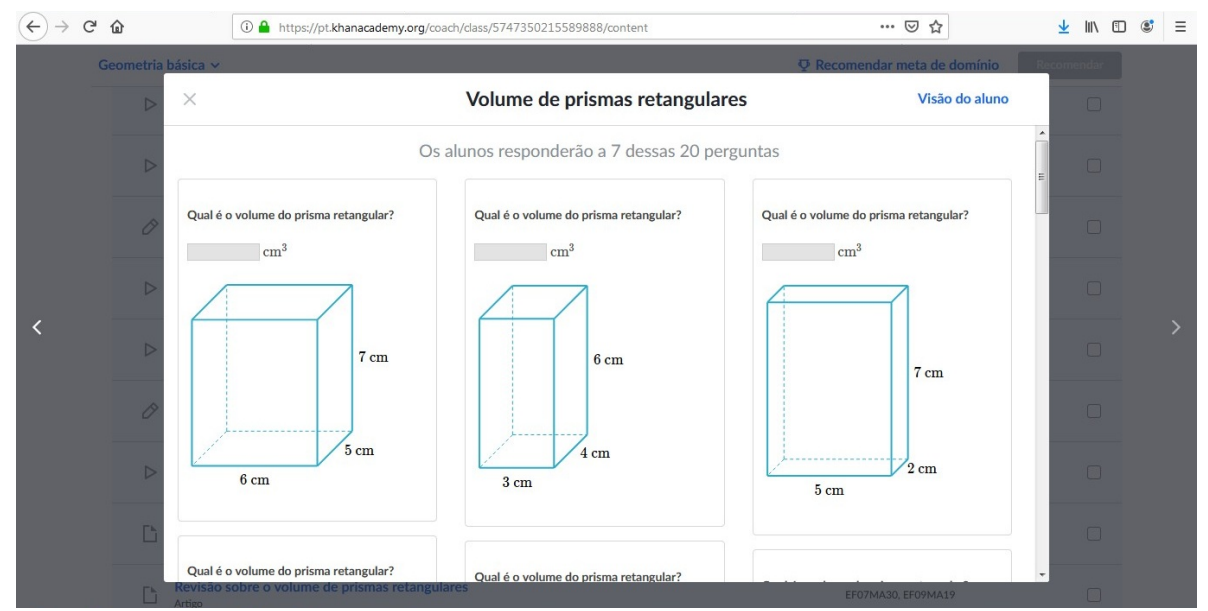

Fonte: Captura de tela na plataforma Khan Academy, 2019.

Após a recomendação feita, o professor-tutor pode acompanhar o progresso de cada aluno através da opção "Recomendações" no menu principal. Nessa opção, poderá saber 
quem já realizou a atividade por meio de "Recomendações por aluno", bem como saber se todos já realizaram a tarefa. Nessa página é exibida o status do progresso de cada aluno, se for um vídeo aparece a mensagem de concluído quando ele já tiver assistido e se for exercícios aparece uma nota de 0 a 100, atribuída de acordo com o desempenho do aluno na resolução das atividades. Esse status além de informar quem já realizou a tarefa, também informa um panorama inicial do desempenho dos alunos no desenvolvimento das tarefas. Na figura 4, podemos observar o status de recomendações da turma do $2^{\circ}$ ano ADM.

Figura 4: Tela do status de realização das recomendações.

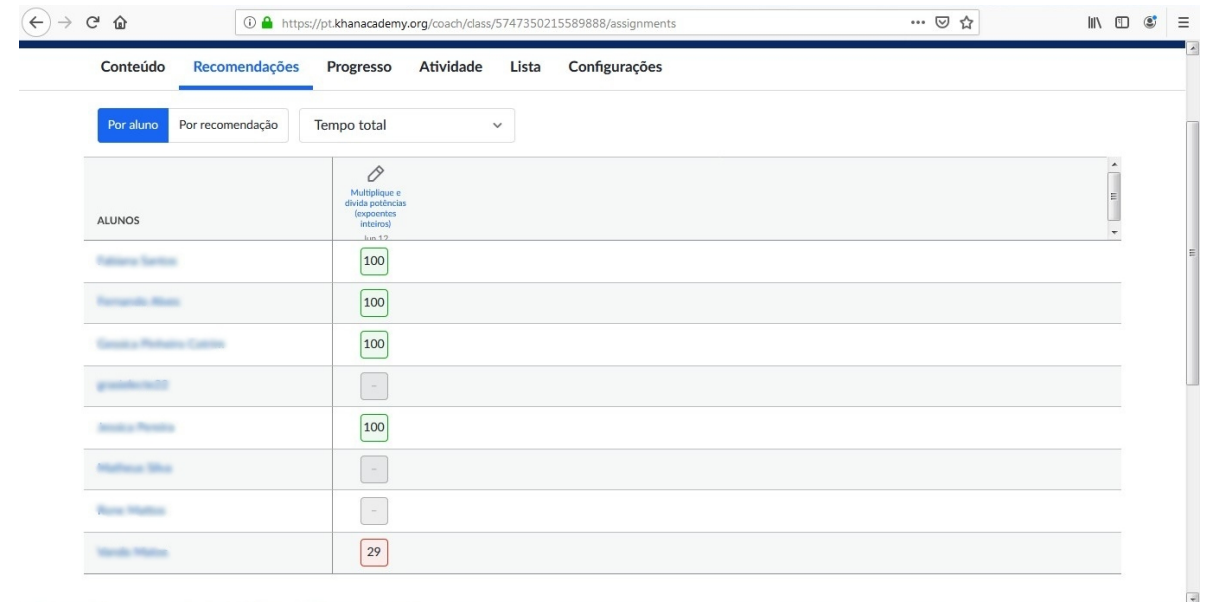

Fonte: Captura de tela na plataforma Khan Academy, 2019.

Logo, quando o aluno termina a recomendação a plataforma disponibiliza um relatório do seu progresso, onde é possível ver os acertos, os erros, as tentativas realizadas e as dicas utilizadas. Essa ferramenta é uma das mais importantes para o tutor que acompanha a turma para poder conhecer onde os estudantes estão errando mais, as dificuldades que são comuns e até mesmo as individuais, as quais na maioria das vezes é difícil perceber em sala de aula, e assim poder reforçar algum conceito com os alunos em sala de aula. Mostraremos, a seguir, o relatório de um aluno da turma do $2^{\circ}$ ano $\mathrm{ADM}$, após concluir a recomendação inicial de multiplicação e divisão de potência. 
Figura 5: Primeira tentativa do aluno nos exercícios de multiplicação e divisão de potência.

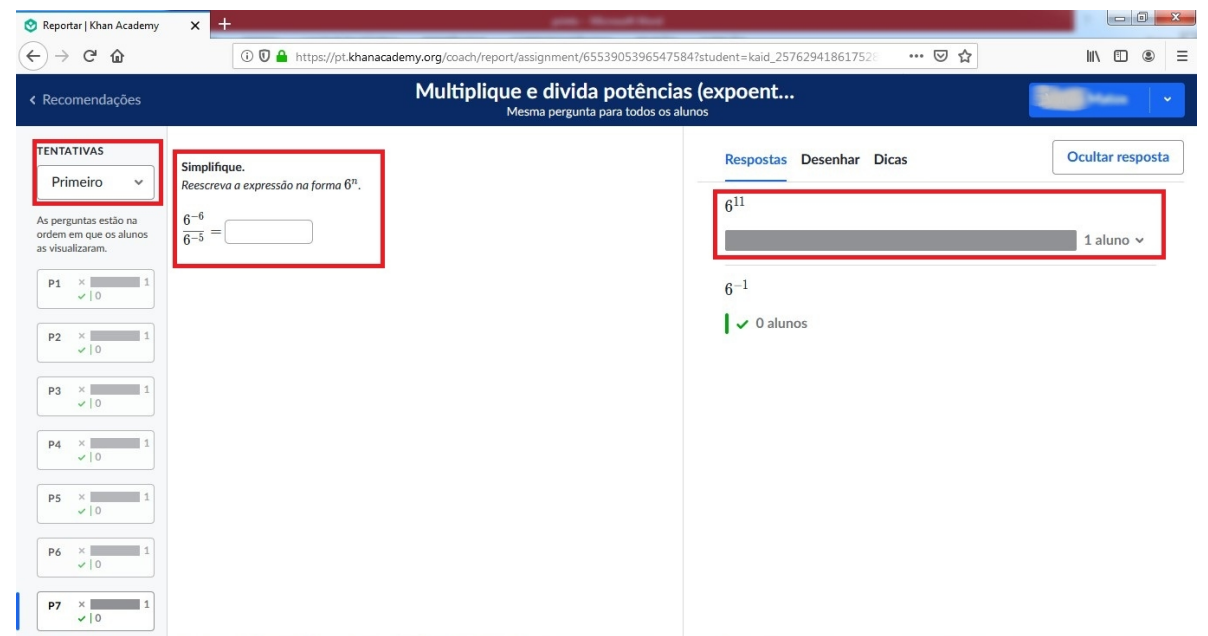

Fonte: Captura de tela na plataforma Khan Academy, 2019.

Temos na figura 5, a primeira tentativa do aluno 2A9 para resolver a primeira recomendação. Nota-se que o aluno não obteve êxito nessas primeiras 7 questões. Porém, o que acontece quando o aluno erra não é a "punição". Pelo contrário, o aluno pode tentar de novo, consultar dicas e assistir vídeo com a explicação de uma questão semelhante. $\mathrm{Na}$ imagem, podemos observar, também, em particular, uma questão destacada no meio da imagem, e a direita em destaque está a resposta dada pelo aluno e abaixo a resposta correta. $\mathrm{Na}$ imagem a seguir, vamos ver o desempenho do mesmo aluno na última tentativa da mesma tarefa.

Figura 6: Última tentativa do aluno nos exercícios de multiplicação e divisão de potência.

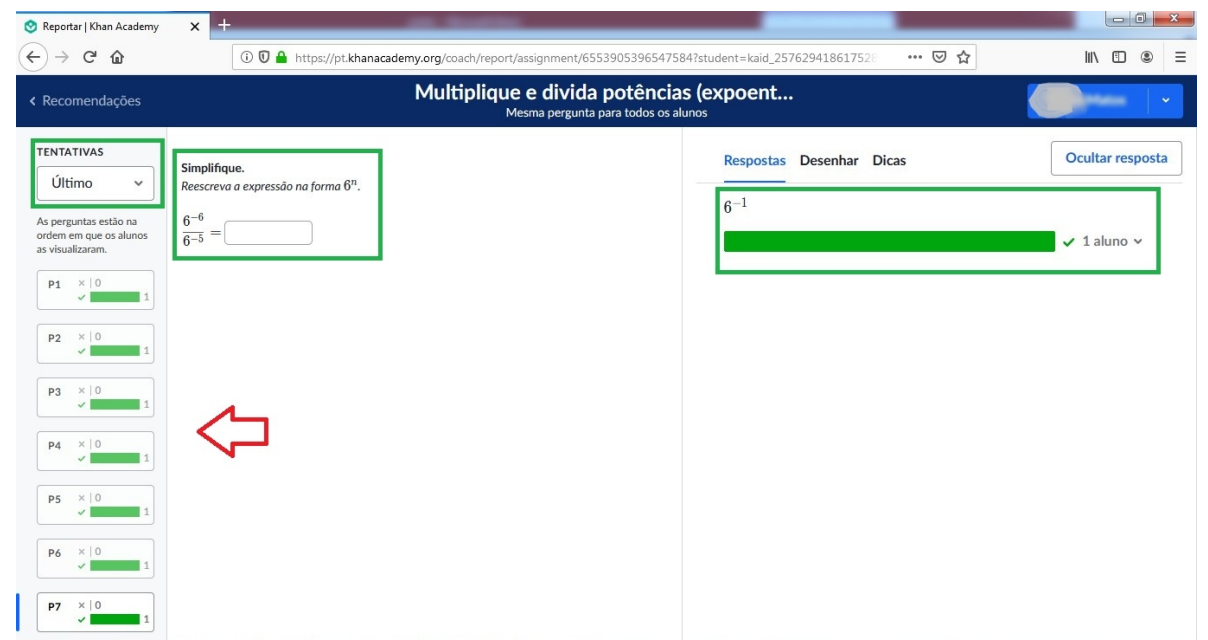

Fonte: Captura de tela na plataforma Khan Academy, 2019.

Podemos observar, na figura 6, que o aluno 2A9 acertou todas as questões dessa vez. Isso mostra que os erros nas tentativas anteriores foram construtivo e, que o suporte dado a 
ele, por meio de exemplos resolvidos e de vídeos, ajudou-o a entender como resolver os exercícios e conseguir êxito dessa vez. Essa situação demonstra que na plataforma o erro é construtivo, isto é, quando o aluno errar ele tem em sua tela possibilidades de superar a dificuldade que foi encontrada, através das dicas com exemplos resolvidos ou sugestão de vídeos sobre aquele assunto. Essas informações disponibilizadas pela plataforma ao professor elucida a usabilidade, a funcionalidade e a potencialidade da Khan Academy no ensino da Matemática e, ainda, abre novas possibilidades de uso podendo, inclusive, melhorar a aprendizagem dos estudantes da turma.

Em outra atividade realizada pela turma do $2^{\circ}$ ano ADM, denominada "Aquecimento: crescimento exponencial versus crescimento linear", foram aplicadas 3 questões para cada aluno responder, visando sondar o conhecimento inicial dos estudantes acerca do conteúdo. Depois das respostas, o professor-tutor teve acesso ao seguinte relatório:

Figura 7: Relatório das respostas da atividade "Aquecimento: crescimento exponencial versus crescimento linear" aplicado na turma dos alunos do $2^{\circ}$ ano ADM.

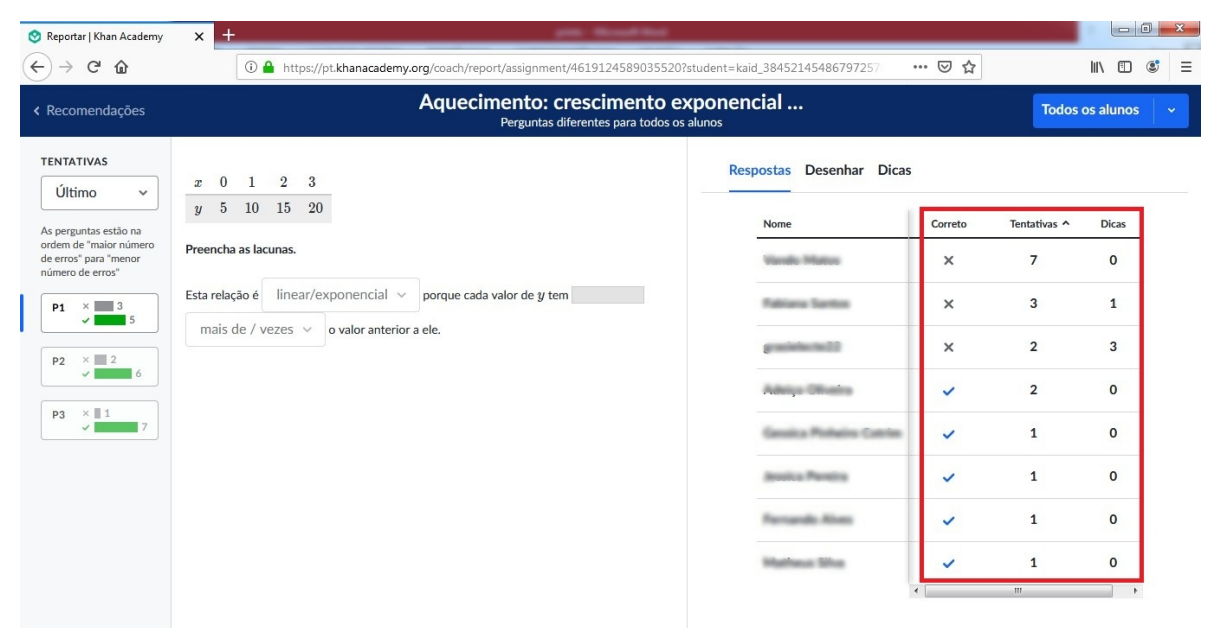

Fonte: Captura de tela na plataforma Khan Academy, 2019.

Vemos que do lado direito da figura 7, sublinhado de vermelho, temos as informações de quem errou e de quem acertou a pergunta 1, a quantidade de tentativas realizadas por cada um e a quantidade de dicas utilizadas pelos alunos. Esses dados possibilitam um panorama das dificuldades e desempenho de cada aluno para o direcionamento do trabalho do professor em sala de aula.

Esses relatórios disponibilizados pela Khan Academy são um dos diferenciais da plataforma em questão, e abrem novas possibilidades de planejamento do trabalho do professor em sala de aula. Essas informações proporcionam um acompanhamento do progresso dos alunos de maneira contínua e individualizada, pois segundo Corrêa (2016, p. 
33), "o professor-tutor pode acompanhar pontualmente as dificuldades enfrentadas por cada estudante e atuar de modo ao aluno avançar apropriadamente em seus estudos".

Dessa forma, é possível ao professor identificar dificuldades ou potencialidades individuais dos alunos, que seriam difíceis de perceber em sala de aula, devido ao ritmo normal da turma. Nessa perspectiva, a Khan é um suporte interessante que vai completar o trabalho da sala de aula tradicional, o que está contemplado na ideia do Ensino Híbrido. O ambiente virtual de aprendizagem, nesse caso, não substitui o presencial, porém, ajuda no planejamento e orientação do trabalho no modelo presencial.

$\mathrm{Na}$ atividade sobre áreas de superfícies, que fora recomendada à turma com alunos do $3^{\circ}$ ano do EM, observaremos na figura 8 , o comportamento dos alunos na resolução de uma questão específica, onde podemos visualizar quem acertou, a quantidade de tentativas realizadas e de dicas utilizadas. Nota-se que a plataforma oferece ferramentas para o aluno solucionar as dúvidas e, assim, progredir no aprendizado.

Figura 8: Tela das tentativas e dicas utilizadas em determinada questão.

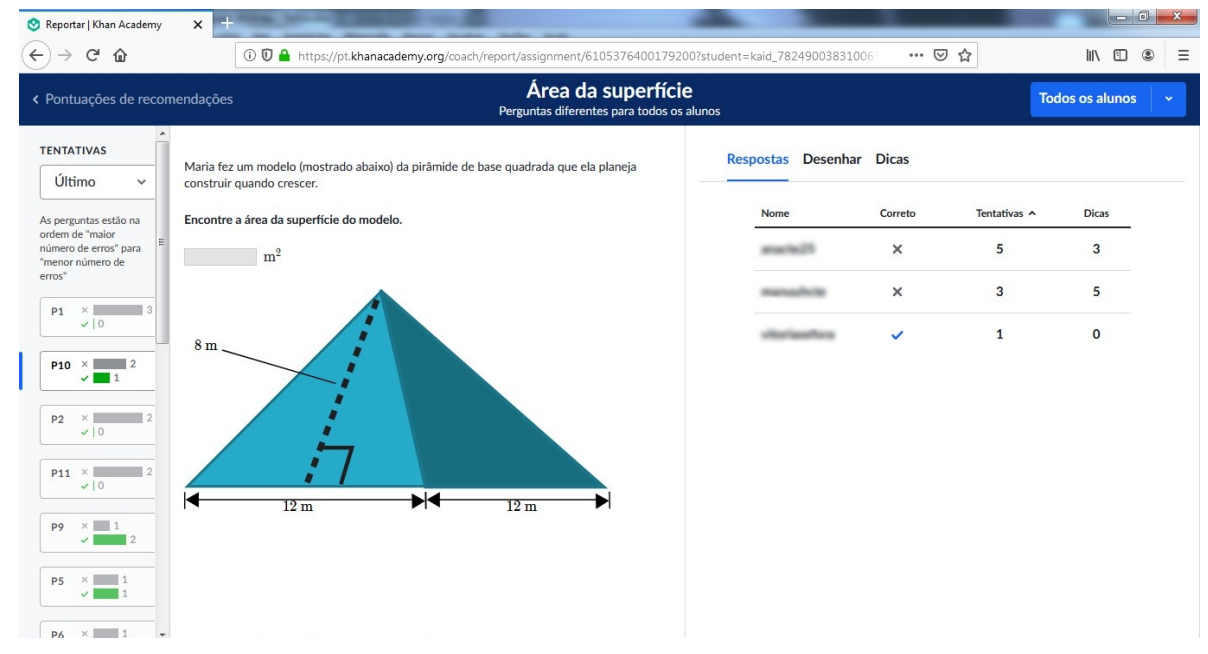

Fonte: Captura de tela na plataforma Khan Academy, 2019.

Além da utilidade desses dados para o professor/tutor, constatamos a interação do aluno na plataforma e seu empenho em estudar e aprender como resolver determinada questão, pois fica demonstrado isso através do quantitativo de tentativas e de vezes em que cada aluno utilizou o recurso das dicas. Percebe-se que a plataforma é diferente, no sentido de oferecer em um só ambiente as ferramentas e recursos para que amplie o seu conhecimento. Veremos a seguir, na figura 9, uma questão específica sobre área de superfície e a dica que foi disponibilizada para o aluno entender melhor como responder a questão. 
Figura 9: Questão área da superfície de pirâmide.

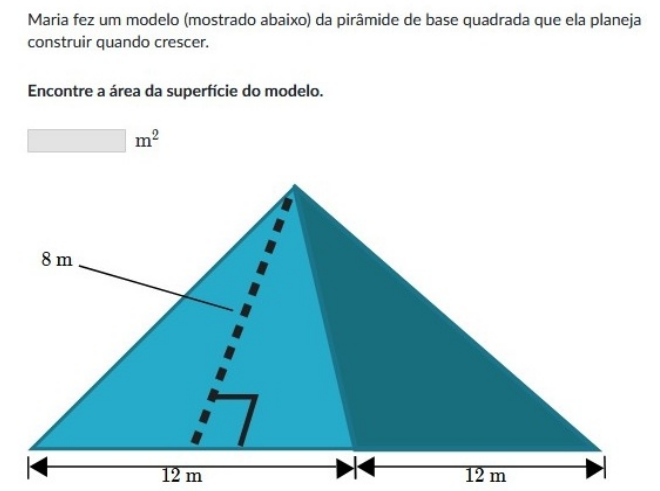

Fonte: Captura de tela na plataforma Khan Academy, 2019.

$\mathrm{Na}$ questão, temos uma situação-problema na qual é solicitado que o aluno calcule a área da superfície de um modelo de pirâmide de base quadrangular. No primeiro momento, o aluno tentará responder a partir do que já sabe, porém se ele errar, serão oferecidas dicas. A respeito dessa questão, a plataforma disponibilizou como dica um exemplo comentado e resolvido passo a passo, como na figura 10. 
Figura 10: Resolução comentada da questão sobre área da superfície da pirâmide.

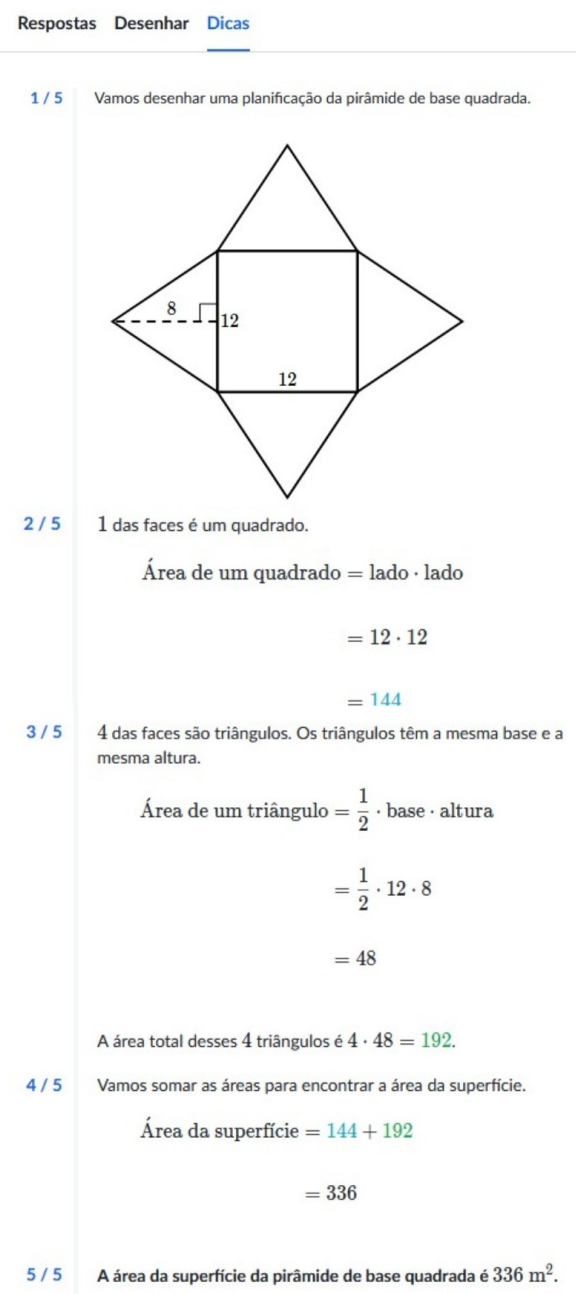

Fonte: Captura de tela na plataforma Khan Academy, 2019.

Podemos notar na dica apresentada, a qual foi retirada da plataforma, e que traz de forma bem explicada a resolução da questão, um recurso importante para ajudar o aluno a compreender como solucioná-la. Então, o aluno pode acessar essa dica quando sentir dificuldade e, a partir dela, tentar resolver outras questões semelhantes. Embora mostremos aqui exemplos específicos de relatórios, questões e dicas, isso se aplica a todas as tarefas desempenhadas pelos alunos no ambiente de interação da plataforma em estudo.

Outro recurso de informação que a Khan Academy oferece no painel do professor-tutor é quanto ao tempo em que o aluno ficou ativo na plataforma, que pode ser acessado na opção "Atividade" do menu principal da turma. É possível ver a hora exata que ele entrou e saiu e o que estava fazendo durante aquele tempo. Todas essas informações estão disponíveis de forma individual, como pode-se observar na figura a seguir. 
Figura 11: Tela de visualização do tempo ativo do aluno na Khan Academy.

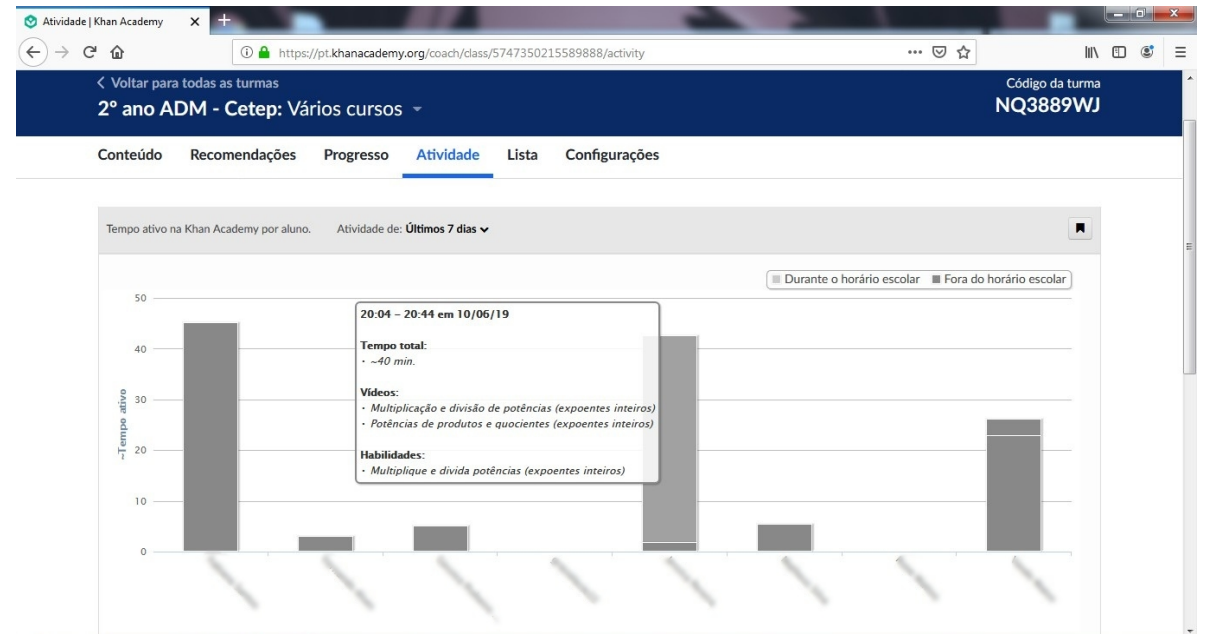

Fonte: Captura de tela na plataforma Khan Academy, 2019.

Por esses gráficos de barra é possível ao professor saber o envolvimento do aluno com a plataforma, quanto tempo ele dispensa no ambiente, qual o horário em que o aluno frequentemente acessa e o que ele mais faz, se assiste mais vídeos aulas ou resolve mais exercícios. A figura 11 mostra que a aluna 2A6 esteve ativa na plataforma por aproximadamente 40 minutos, na noite do dia 10.07.2019, assistiu 2 vídeos e conquistou uma habilidade quando testada/praticada em exercícios pelo ambiente. Essas informações são importantes para o professor saber qual está sendo a dedicação dos alunos, quem está conseguindo estudar mais e, a partir disso, buscar saber quais as dificuldades daqueles que estão estudando menos, no sentido de ajudá-los a progredir também.

Portanto, apresentamos até aqui algumas das possibilidades e benefícios do uso da plataforma Khan Academy como ferramenta de auxílio para o ensino e aprendizagem de Matemática. A seguir, conheceremos o que disseram os participantes da pesquisa a partir das experiências vivenciadas por eles durante o desenvolvimento do trabalho.

\section{A opinião dos estudantes participantes como resultado da experiência}

Após a realização da oficina, os estudantes responderam a um questionário por meio do Google Forms, pelo qual puderam expressar as suas opiniões sobre a plataforma Khan Academy. O objetivo foi dar voz aos estudantes para que também pudessem avaliar a plataforma em questão e que fosse possível, a partir dessas respostas, fazermos uma análise da percepção deles referentes ao ambiente virtual de aprendizagem em estudo.

Então, foi disponibilizado a todos os participantes da pesquisa o link de acesso ao formulário do Google Forms por meio do aplicativo de mensagens WhatsApp. Após todos 
terem respondido, foram organizados os dados. Inicialmente, procuramos saber se o primeiro contato dos alunos com a Khan Academy foi durante a realização da pesquisa ou se alguém já tinha utilizado a plataforma antes. $90 \%$ dos alunos responderam que não tinham acessado a plataforma antes.

Porém, ao perguntarmos se houve alguma dificuldade em relação a navegação no ambiente virtual da Khan Academy, 60\% afirmaram terem tido facilidade e que a mesma é de fácil navegação, corroborando que a "interface da plataforma Khan Academy é bem ilustrativa e de fácil acesso a todas as informações", como afirma CORRÊA (2016, p. 15). No entanto, uma minoria teve alguma dificuldade inicial devido a não familiaridade com a plataforma.

Sobre o que achavam a respeito da gamificação da plataforma (pontos de energia e as medalhas), os alunos consideraram ser uma motivação a mais e, consequentemente, dedicar mais tempo de estudo neste ambiente de aprendizagem. Essa percepção tem explicação na Neurociência, pois segundo Sanjaume (2016), "o desafio, as recompensas e a vontade de superação são componentes que perseguem o cérebro, pois permitem a ativação neuronal, favorecendo um contexto de aprendizagem" (SANJAUME, 2016, p. 6). Ou seja, os pontos de energia que a plataforma oferece motiva o aluno a realizar mais atividades e as medalhas incentivam a avançar e superar níveis de conteúdo, o que é positivo para a aprendizagem, pois ativa as potencialidades do aluno e instiga a sua curiosidade pelo conhecimento. Sendo assim, o aluno passa a ter satisfação pelo que está fazendo e, com isso, aprende mais.

Tendo em vista que os pontos de energia e as medalhas geram esse estímulo positivo nos estudantes, fica evidente ser uma vantagem que a plataforma Khan Academy apresenta. Esse tipo de recompensa também pode ser usado pelo professor para fazer ranking entre os alunos da turma e incentivá-los ainda mais através de torneios e campeonatos, por exemplo. Entretanto, essas recompensas têm um objetivo primordial, que é fazer com que o aluno prossiga e conquiste habilidades.

Os pontos de energia podem ser conquistados de várias formas, seja na audiência das vídeo-aulas, na resolução de exercícios, na leitura de uma dica, em todo o tempo que o aluno está ativo na plataforma praticando algo, ele receberá os pontos de energia. No entanto, praticar tudo isso não é apenas por recompensas, mas por aprendizado também. Dessa forma, as vídeo-aulas buscam esclarecer dúvidas dos conteúdos de forma prática sempre por meio de questões. Esse método usado pela Khan Academy, de explicar o conteúdo que está sendo estudado através de exemplos, está associado ao fato que 
[...] quando você está começando a tentar entender como resolver um problema, você está sob uma pesada carga cognitiva - e por isso começar com um exemplo totalmente solucionado ajuda. É como usar um GPS quando você está dirigindo por ruas desconhecidas no meio da noite. (OAKLEY apud CORRÊA, 2016, p. 18).

Por isso, quando está estudando algum conteúdo na Khan Academy, inicialmente, o estudante assistirá um vídeo com um exemplo resolvido e explicado. Conforme o aluno vai dominando habilidades e avançando de nível, consequentemente aumenta o patamar dos exemplos resolvidos e explicados nos vídeos, com isso o educando avança no conteúdo e na consolidação de conceitos da Matemática.

Dessa forma, foi perguntado aos alunos a opinião deles quanto aos vídeos que a plataforma oferece. $60 \%$ consideraram que os vídeos são muito bons e que apresentam uma linguagem clara e de fácil entendimento.

A partir das respostas dadas, para os outros $40 \%$ dos estudantes, os vídeos foram razoavelmente bons ou indiferentes. Essa impressão pode estar ligada ao fato de que a abordagem utilizada neles seja semelhante ao método utilizado por muitos professores em aulas meramente expositivas, com apenas resolução de exemplos, porém, sabemos que esse método, apesar de ser repetitivo, é necessário para poder explicar a resolução de questões.

Nesse sentido, os exercícios e problemas da plataforma são importantes e propostos com o objetivo de que os alunos possam praticar o conteúdo que está sendo estudado e dominar as habilidades necessárias. Sabemos que os exercícios e problemas são o principal meio de praticar e avaliar o conhecimento de determinado assunto em Matemática, pois segundo Dante (1998), estes fazem com que o conteúdo seja mais interessante e desafiador, desenvolvem o raciocínio e o pensar produtivo e dão ao aluno a oportunidade de se envolver com as aplicações da Matemática, bem como são um meio de avaliação da aprendizagem.

Cerca de $90 \%$ dos participantes dessa pesquisa gostaram dos exercícios e problemas oferecidos na plataforma. Esse resultado pode estar associado ao fato de que esses exercícios e problemas, na sua maioria, são bem dinâmicos, apresentando imagens ilustrativas e até mesmo manipuláveis, além de que, na tela dos exercícios, é possível utilizar calculadora, desenhar, consultar uma dica, ver um exemplo, tudo isso de modo fácil, rápido e prático. Esses elementos somados aos incentivos dos pontos de energia e medalhas motivam os estudantes a resolverem mais questões, explorando e aprendendo conceitos e conquistando habilidades. 
Foi possível observar que os exercícios e problemas realizados pelos alunos na plataforma foram muito úteis para o desenvolvimento do conteúdo estudado em sala de aula, pois serviram de complemento à tradicional lista de exercícios de fixação. O diferencial era que, além de poderem conferir a resposta de imediato, ainda tinham disponíveis as dicas, exemplos resolvidos e até mesmo vídeos com a explicação de questões de mesmo nível do conteúdo. Desse modo, a Khan Academy pode ser um complemento das listas de exercícios, sendo possível ao professor acompanhar através dos relatórios o desempenho de cada um e quem realmente está fazendo.

Nesse sentido, as contribuições da Khan Academy nos estudos dos alunos foram relatadas a partir das experiências que cada um obteve na plataforma. Abaixo, algumas das percepções dos estudantes coletadas pelo questionário: "Bom minha experiência para com a plataforma Khan Academy foi bem
legal gostei bastante além dos exercícios propostos há uma complementação
com vídeos aulas explicativas que são de extrema importância para a
resolução dos exercícios assim contudo a aprendizagem aumenta bastante
por ser é um complemento importante nos estudos junto com as aulas
presenciais assim." - (Aluna 2A2)
"A oficina trouxe uma nova forma de estar aprendendo o conteúdo e isso é
algo muito bom pois nos auxilia em dúvidas sendo que é de fácil acesso." -
(Aluna 2A6)
"Tranquila, mas a plataforma é bem complicada. No fim, acabei gostando."
-(Aluna 3A1)
"Legal, aprendi novas coisas, de maneira mais fácil e divertido." - (Aluno
2A1)

A partir dessas colocações, é possível deduzir que, apesar da pesquisa ter sido realizada em pouco tempo, os alunos conseguiram vivenciar experiências produtivas por meio da plataforma Khan Academy. Essas experiências contribuíram para o aprendizado do conteúdo que estava sendo desenvolvido em sala de aula, possibilitando aos estudantes conhecerem essa ferramenta digital de aprendizagem de Matemática que se apresenta de forma atual, com elementos que estão cada vez mais presentes na vida social e nas interações digitais dos estudantes das novas gerações.

Por meio da Khan Academy, é possível tornar a sala de aula um ambiente de interação, investigação e propício a diálogos/devolutivas sobre as dificuldades em comum ou individualizadas, a partir das informações disponíveis nos relatórios de monitoramento da própria plataforma. Vale ressaltar que é importante que os estudantes tenham uma postura 
crítica, tendo controle daquilo que desenvolvem no ambiente virtual e, até mesmo, em outras situações do "mundo virtual".

Os resultados reafirmam que os recursos e ferramentas da era digital são importantíssimos para a Educação. Não se pode mais ignorar as tecnologias disponíveis na atualidade, sendo que elas fazem parte da cultura dos chamados nativos digitais que são nossos estudantes atualmente. No entanto, ressaltamos que toda tecnologia é humana, portanto, não funcionará como o desejado sem a correta intermediação do ser humano. Logo, na Educação não é diferente, cabendo ao professor fazer a mediação adequada na relação aluno, ferramenta digital e conhecimento.

Ademais, o uso de ferramentas digitais na Educação, apoiado na perspectiva do Ensino Híbrido, em nenhum momento tem a finalidade de sobrepor o ensino a distância em comparação ao ensino presencial. A ideia é que os recursos digitais sejam aproveitados como complemento da sala de aula presencial e que influenciem positivamente no processo de ensino e aprendizagem, gerando conhecimento, habilidades e competências.

Por fim, consideramos a Khan Academy uma possibilidade para potencializar e auxiliar o ensino e aprendizagem de Matemática pois os resultados dessa pesquisa demonstram que sua metodologia de abordagem e de funcionamento impulsionam novos conhecimentos e saberes fundamentais para o processo formativo do aluno. No entanto, devese esclarecer que a proposta desse trabalho não é ignorar as muitas dificuldades e mazelas do cenário educacional brasileiro e mostrar um contexto surreal, mas é desejo motivar os professores a buscar inovações e enfrentar os desafios que estão postos atualmente, tendo a plataforma Khan Academy como uma possível aliada.

\section{Considerações Finais}

A utilização das TDICs pode trazer vantagens para o aprendizado do aluno, sendo possível combinar o ensino presencial com o ensino remoto, na medida que existem ferramentas capazes de auxiliar nesse processo, proporcionando a possibilidade de ampliação do estudo além do horário e da sala de aula tradicional. Durante a pandemia do COVID-19, percebemos o quanto as TDICs foram fundamentais para assegurar o direito constitucional à Educação.

Desse modo, para ampliar as possibilidades de adquirir conhecimento, não podemos ignorar as TDICs, sobretudo, no contexto atual. E, quando falamos do ensino e aprendizagem de Matemática, constatamos que a ferramenta que pode auxiliar nesse processo é a Khan 
Academy, por possibilitar o estudo da disciplina de forma personalizada à necessidade do aluno, com uma estrutura diferenciada baseada em games e que oferece feedback tanto para o estudante quanto para o professor. Acrescentamos que, durante as aulas remotas e híbridas, no decorrer do período pandêmico, a Khan Academy foi amplamente utilizada por professores como uma das ferramentas on-line de ensino da Matemática.

Portanto, a partir das reflexões expostas, consideramos a plataforma Khan Academy uma ferramenta que pode auxiliar no ensino e aprendizagem de Matemática, uma vez que o portal pode atuar como um ambiente para o complemento do estudo dos alunos, possibilitando estudar em casa, no horário que convém, com acesso a amplos conteúdos disponibilizados em vídeos, textos e exercícios que podem expandir o aprendizado tido em sala de aula.

Não temos dúvidas que apenas afloramos a discussão sobre o uso da Khan Academy. Naturalmente haverá mais trabalhos que continuarão investigando essa temática, oferecendo contribuições significativas à Educação, em especial à Educação Matemática.

\section{Referências}

AUSUBEL, D. P. The Psychology of Meaningful Verbal Learning. New York: Grune \& Stratton, 1963.

AZEVEDO, A. B.; MORAES, C. A. do P. Khan Academy: uma ferramenta de auxílio no processo de ensino/aprendizagem da matemática. Educação e Linguagem, v. 20, n. 1, p. 167-182, 2017. Disponível em: <https:/www.metodista.br/revistas/revistasmetodista/index.php/EL/article/view/8717/6214>.

BACICH, L.; NETO, A. T.; TREVISANI, F. M. Ensino híbrido: personalização e tecnologia na educação. Porto Alegre: Penso, 2015.

BICUDO, Maria Aparecida Viggiani. Pesquisa em Educação Matemática. Revista ProPosições, v. 04, n. 01 [10], p. 18-23, março de 1993.

BIERWAGEN, G. S. Plataforma Khan Academy na educação básica. CIET:EnPED, 2018. ISSN 2316-8722. Disponível em:

$<$ http://cietenped.ufscar.br/submissao/index.php/2018/article/view/825>.

BOGDAN, Roberto C.; BIKLEN, Sari Knopp. Investigação qualitativa em educação: uma introdução a teoria e aos métodos. Porto: Porte Editora, 1994. 
BORBA, M. C.; PENTEADO, M. Informática e Educação Matemática. 3. ed. Belo Horizonte: Autêntica, 2007.

CHRISTENSEN, C. M.; HORN, M. B.; STAKER, H. Ensino híbrido: uma inovação disruptiva? Clayton Christensen Institute, 2013. Disponível em: <https://www.pucpr.br/ wpcontent/uploads/2017/10/ensino-hibrido_uma-inovacao-disruptiva.pdf $>$.

CORRÊA, P. M. H. A plataforma Khan Academy como auxílio ao ensino híbrido em Matemática: um relato de experiência. Dissertação (Mestrado) — PROFMAT, Rio Grande, 2016.

DANTE, L. R. Didática da Resolução de Problemas de Matemática. 2. ed. São Paulo: Ática, 1998.

DUARTE, P. V. C. Plataforma Khan Academy: uma análise de suas potencialidades na visão de professores do Ensino Fundamental I de um município do interior de São Paulo. Dissertação (Mestrado) - Mestrado em Educação, São Carlos, 2018.

FARDO, M. L. A gamificação como estratégia pedagógica: Estudo de elementos dos games aplicados em processos de ensino e aprendizagem. Dissertação (Mestrado) - Universidade de Caxias do Sul, Curso de Pós-Graduação em Educação, Caxias do Sul, 2013.

HENRIQUES, A. Dinâmica dos elementos da geometria plana em ambiente computacional Cabri-Géomètre II. Ilhéus: Editora Editus, 2001.

LIBÂNEO, J. C. Exigências educacionais contemporâneas e meios de comunicação. São Paulo: Senac, 1996.

MENEGAIS, D. A. F. N. A Formação Continuada do Professor de Matemática: Uma inserção tecnológica da plataforma Khan Academy na prática docente. Tese (Doutorado) Universidade Federal do Rio Grande do Sul, Porto Alegre, 2015.

MOREIRA, M. A. Aprendizagem significativa crítica. Instituto de Física da UFRGS, Porto Alegre, 2005.

PAPERT, Seymour. A Máquina das Crianças: Repensando a Escola na Era da Informática. Porto Alegre: Artes Médicas, 1994.

PAPERT, Seymour. LOGO: Computadores e Educação. São Paulo: Brasiliense, 1986.

PERICO, L. A. S. Ensino Médio, Língua Portuguesa e Portal Educacional: percepções emergentes das narrativas de alunos inseridos em práticas de letramento digital. Dissertação 
(Mestrado) - Faculdade de Humanidades e Direito, Universidade Metodista de São Paulo, 2015.

RAPOSO, A. B. Introdução à interação humano-computador. PUC, Rio de Janeiro, 2012. Disponível em: $<$ http://www.inf.puc-rio.br/ inf1403/docs/alberto2012-

1/06_AvHeuristica.pdf>. Acesso em: 17 julho 2019.

SANJAUME, N. G. Neuroeducação e jogos de mesa. Dharma Factory, 2016. Disponível em: $<$ http://devir.com.br/arquivos-downloads/Neuroeducacao_PT_final_CORRIGIDO.pdf $>$.

Recebido em 13 de setembro de 2021.

Aprovado em 19 de outubro de 2021. 